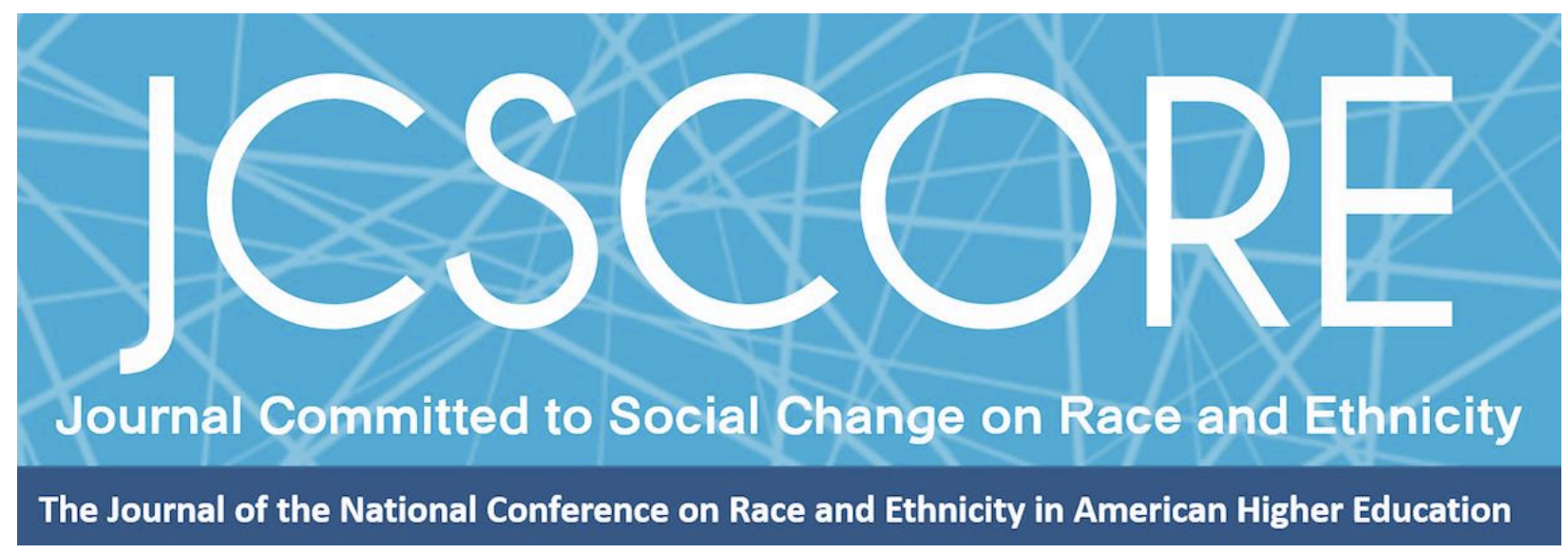

\title{
WHITENESS AND THE RAINBOW: WHITE LGBTQ+ COLLEGE STUDENTS' RACIAL IDENTITY DEVELOPMENT
}

\author{
Chelsea E. Noble \\ Michigan State University \\ Kristen A. Renn \\ Michigan State University
}

Journal Committed to Social Change on Race and Ethnicity

Volume 7, Issue 2 | 2021

\author{
Copyright and Open Access \\ (c) 2021 Chelsea E. Noble, Kristen A. Renn

\section{(c) (1) (2) (2)}

This work is licensed under a Creative Commons Attribution-NonCommercial-ShareAlike 4.0 International License. Permission of the authors is required for distribution and for all derivative works, including compilations and translations. Quoting small sections of text is allowed as long as there is appropriate attribution and the article is used for non-commercial purposes.

The Journal Committed to Social Change on Race and Ethnicity (ISSN 2642-2387) is published by the National Conference on Race and Ethnicity (NCORE), a production of the University of Oklahoma, in partnership with the University of Oklahoma Libraries. 


\title{
Whiteness and the Rainbow: White LGBTQ+ College Students' Racial Identity Development
}

\author{
Chelsea E. Noble \\ Michigan State University \\ Kristen A. Renn \\ Michigan State University
}

\begin{abstract}
LGBTQ+ communities and spaces on college campuses are often known as whitecentered spaces, implicitly or explicitly excluding students of color. While White LGBTQ+ students may experience marginalization and exclusion on the basis of their sexual orientations and/or gender identities, they may unwittingly perpetuate oppression on the basis of race. Utilizing Helms' (1990) white racial identity development model, this study explored how White LGBTQ+ college students understand their racial identity and white privilege. The sample of 12 White LGBTQ+ college students was drawn from a larger four-year longitudinal qualitative study of LGBTQ+ college student success. In early interviews, students either did not discuss their white racial identity or did not view their white racial identity as a salient aspect of their identity. However, students increasingly spoke about their white identities, race, and racism in later interviews. Interpersonal experiences, academic engagement, and national events provided access points for White LGBTQ+ students to talk about race and their white identities. Implications for research and practice with White LGBTQ+ college students and in LGBTQ+ campus spaces are discussed.
\end{abstract}

Lesbian, gay, bisexual, transgender, and queer (LGBTQ+) college and university campus spaces and groups are often known as white-centered and exclusionary (Mitchell \& Means, 2014; Nicolazzo, 2017). For example, LGBTQ+ campus resource centers and groups exist to serve LGBTQ+ students, but they may not be welcoming or safe for either LGBTQ+ students of Color or LGBTQ+ center staff members of Color (Johnson \& Javier, 2017; McCoy, 2018; Miller \& Vaccaro, 2016; Ortiz \& Mandala, 2021). White LGBTQ+ college students' conceptualization of whiteness and racial privilege can 
Journal Committed to Social Change on Race and Ethnicity | Volume 7, Issue 2 | 2021

influence how inclusive LGBTQ+ spaces and communities are for Queer and Trans People of Color (QTPOC).

White LGBTQ+ people often experience marginalization on the basis of sexual orientation and/or gender, yet have minimal understanding of the privilege they experience based on their racial identity. Over the course of a two-year ethnographic study of LGBT campus climates, Vaccaro (2012) found a paucity of attention to racial issues among study participants "[since] many participants were White" (p. 439). In another study, White queer students created hostile environments for queer student leaders of Color and refused to attend to issues of race because they wanted to "just [be] gay" (Miller \& Vaccaro, 2016, p. 48). For some White people, experiencing marginalization around one aspect of their identity, such as gender or sexuality, can lead to increased awareness of other aspects of their identity, including their racial identity (e.g., Maxwell, 2018). Drawing on personal experiences of a different marginalized social identity can be a helpful tool for people who are beginning or deepening their understanding of racial privilege/oppression dynamics. However, this process of drawing on a marginalized identity may inadvertently perpetuate racism and white supremacy by centering White people and their processing (Grillo \& Wildman, 2018).

This study adds to scholarship of the intersections of race, gender, and sexuality, which has, to this point, largely and appropriately focused on QTPOC (Duran, 2019). There has been little attention to white racial identity among LGBTQ+ student research, although scholars have and continue to critique the whiteness of LGBTQ+ spaces (e.g., Self \& Hudson, 2015), as well as the effects of whiteness in higher 
Journal Committed to Social Change on Race and Ethnicity | Volume 7, Issue 2 | 2021

education on transgender students (Stewart \& Nicolazzo, 2018). The purpose of this exploratory study was to examine how White LGBTQ+ college students conceptualize their racial identity and engage with race in their lives. This decision inherently centers White students, the dominant group, which is in tension with anti-racist work that seeks to center the experiences of People of Color (Bonilla-Silva, 2017). Yet, as Matias (2016) argued, "the onus of liberation cannot be placed solely on the backs of the oppressed" (p. 164). While racism is structural and systemic, a piece of addressing it is to seek to "change [White people's] views and move them to be part of the movement to advance racial justice" (Bonilla-Silva, 2017, p. 240).

With sensitivity to these dynamics of racial power and privilege, we examined how White LGBTQ+ students described race broadly and their own racial identity over the course of four years. The research questions guiding our inquiry were: 1) How do White LGBTQ+ college students understand their racial identities? And, 2) Which contexts and experiences prompt White LGBTQ+ college students to examine their racial identities, white privilege, and white supremacy? In order to address these questions, we begin by reviewing relevant literature and situating the present study through Helms's (1990) white racial identity development model. With this backdrop, we describe our four-year, qualitative longitudinal study and findings. We conclude with implications for research and practice with LGBTQ+ students, with particular attention to White LGBTQ+ students.

\section{Literature Review}

There has been limited attention to white identity among LGBTQ+ college students. Similarly, there has been limited attention to gender and sexuality in white 
Journal Committed to Social Change on Race and Ethnicity | Volume 7, Issue 2 | 2021

racial identity and Critical Whiteness Studies, especially situated within higher education. In order to contextualize this study, it is necessary to draw from research on LGBTQ+ students as well as scholarship on how White students learn about white identity, privilege, and immunity.

\section{LGBTQ+ College Students}

LGBTQ+ college students are the focus of a substantial amount of research (Duran, Jackson, \& Lange, 2020). However, "White, able-bodied, and middle-class are assumed norms" (Renn, 2010, p. 135) in much of this scholarship. Increasingly, scholars are attending to the intersections of race, ethnicity, gender, and sexuality (e.g.,

Duran, 2019; Johnson \& Javier, 2017; Lange et al., 2019).

The recent body of literature explores LGBTQ+ student belongingness (Duran, Dahl, et al., 2020), academic experiences (Beattie et al., 2021; Friedensen et al., 2021; Linley et al., 2018), and campus experiences (Garvey et al., 2018; Woodford et al., 2017), as well as the institutional structures intended to support LGBTQ+ students, including LGBTQ+ campus resource centers (Marine \& Nicolazzo, 2014; Pitcher et al., 2018; Self \& Hudson, 2015). While the default population generally has been White LGBTQ+ students (Lange et al., 2019; Renn, 2010), scholars have attended to race in varied ways in LGBTQ+ college student literature. For example, Abes and Jones (2004) intentionally incorporated students' multiple identities, including race, in their study of lesbian college students' meaning making about their identities. Rather than the othering practice of relegating QTPOC to one chapter in an edited volume, Stewart et al. (2015) intentionally had students' multiple identities, including race, integrated into each chapter. Nicolazzo (2017) highlighted moments when racial dynamics significantly 
Journal Committed to Social Change on Race and Ethnicity | Volume 7, Issue 2 | 2021

distinguished Black trans ${ }^{*}$ students' experiences from White trans ${ }^{*}$ students' experiences.

In broader discussion of LGBTQ+ spaces, QTPOC have reported marginalization, exclusion, and their experiences of LGBTQ+ spaces as white spaces (Logie \& Rwigema, 2014; McCready, 2004; Mitchell \& Means, 2014). LGBTQ+ scholarship focused specifically on QTPOC in higher education has developed over the last 20 years (Duran, 2019). In Duran's (2019) systematic review of research about queer students of Color, four major themes emerged from 68 empirical studies and scholarly pieces: coming out and support, campus climate and single-identity spaces, complex individuality, and insufficient resources and representation. QTPOC often feel excluded from both queer and trans spaces as well as racial affinity spaces (Duran, 2019; Johnson \& Javier, 2017). Johnson and Javier (2017) urged LGBTQ+ resource center staff, who are often White, to "continue to examine whether their spaces are safe and welcoming for students of color" (p. 6). Increasing attention to the intersections of gender, sexuality, race, and ethnicity among LBGTQ+ college students is an important component to creating more inclusive, more equitable, and more just campuses.

\section{Learning about White Racial Identity and Whiteness}

White racial identity is a socially constructed category, typically ascribed on the basis of one's skin color (Leonardo, 2009). Distinct from white racial identity and White people, whiteness is "an ideology of interlocking tacit assumptions that shape and support racism, patriarchy, classism, ableism, ageism, religious hegemony, trans* oppression, heterogenderism, and settler colonialism" (Stewart \& Nicolazzo, 2018, p. 134). Whiteness frequently operates within and through racism, "a network of social 
Journal Committed to Social Change on Race and Ethnicity | Volume 7, Issue 2 | 2021

relations at social, political, economic, and ideological levels that shapes the life chances of the various races" (Bonilla-Silva, 2017, p. 18). Racism manifests through individual attitudes, institutions (e.g., social structures, laws, and policies), and cultural beliefs (Helms, 1990). Anti-racism, in response, aims to resist or dismantle racism in its many forms (Omi \& Winant, 2015). The framework for this study is white racial identity development, which attends to how White people become conscious of their white racial identity and seek to develop a positive anti-racist White identity (Helms, 1990).

In a study of White college men, they frequently minimized the role of race and racial issues, ultimately demonstrating little change in their views of race and racism during college (Cabrera, 2014). White people often inhabit racially homogenous communities and attend racially segregated schools, so college may be one of White students' early opportunities to interact with People of Color (Lichter et al., 2017; Tatum, 2017). White college men most often learned about their white identities and whiteness through interactions with People of Color, formal education experiences, and holding one or more minoritized identities, such as sexuality or religion (Cabrera, 2012). Ecological perspectives aid the analysis of these experiences, shifting attention from the individual to the environments, people, and other forces with which the individual interacts (Renn \& Arnold, 2003). White students frequently begin their (un)learning about race, their own racial identity, and living in a white supremacist society with "a push from an entity (person/experience/locale) outside of a White individual" (Cabrera et al., 2016, p. 129).

Intergroup contact has long been associated with the reduction of intergroup prejudice, including majoritized and minoritized racial groups (Allport, 1954; Tropp \& 
Journal Committed to Social Change on Race and Ethnicity | Volume 7, Issue 2 | 2021

Pettigrew, 2005). Members of majority racial-ethnic groups (White people) were more likely to benefit from intergroup contact in the reduction of prejudice than minoritized status groups (People of Color; Tropp \& Pettigrew, 2005). Institutions and related organizations with lower structural diversity, and thus fewer people with minoritized identities, may have fewer opportunities for cross-racial interactions (Grier-Reed et al., 2017). Yet, higher levels of cross-racial interactions are significantly associated with desirable college student outcomes, including positive racial attitudes, interest in democratic participation, and general emotional wellbeing (Bowman \& Park, 2015). White students in highly racially homogenous spaces, such as fraternities, report few conversations about race and little reflection on their racial identities (Joyce \& Cawthon, 2017). To promote engagement, reflection, and anti-racist action among White students, scholars have advanced strategies including intergroup dialogue programs, workshops, academic coursework, and co-curricular opportunities (Grier-Reed et al., 2017; Reason, 2015). There are also opportunities to encourage cross-racial interactions in religious groups (Park \& Bowman, 2015). In these spaces, faculty, student affairs practitioners, and peers can engage in conversations about race and foster connections across racial divisions.

Often, these strategies approach conversations on race with White students through the lens of white privilege (Cabrera, 2017). White privilege refers to the unearned advantages that White people enjoy on the basis of the color of their skin (McIntosh, 1989). While discussions of white privilege can be a productive entry point to increasing racial awareness for White people, this approach promotes an individual focus, rather than attention to the structural issue of white supremacy. Cabrera (2017) 
Journal Committed to Social Change on Race and Ethnicity | Volume 7, Issue 2 | 2021

offered the language of "White immunity" (p. 81) to more accurately capture the reality that People of Color are not and have not been assured of just or equitable social and legal treatment while White people are shielded from this treatment. This shift in language promotes a new lens for educators "to engage, challenge, and develop White students' racial awareness while linking it to their responsibility for engaging in racial justice praxis" (Cabrera, 2017, p. 88). Further, white immunity is a useful framing for examining individual-level phenomena, such as White people's insulation from considering race and their ability to remain willfully ignorant of racial issues (Cabrera, 2018). Discussions of white immunity are compatible, and perhaps key, to leveraging common strategies more effectively for anti-racist ends at the individual and systems levels.

\section{Framework}

Whiteness is a socially constructed system that produces and maintains dominance by "[centering] and [privileging] certain habits, beliefs, and ways of being as

normal, optimal, and preferred" (Stewart \& Nicolazzo, 2018, p. 135). White people exist within and benefit from Whiteness. However, White people do not have to passively accept whiteness' promises of privilege and supremacy for themselves and the associated subordination of People of Color. Indeed, understanding systems of dominance at the interpersonal and systems levels and working to combat them are key aspects of developing a positive white racial identity (Malott et al., 2015).

Multiple white racial identity development models have proposed that the development of a positive white racial identity requires two major actions: rejecting racism and adopting a non-racist white identity (Helms, 1990). In Helms's (1984, 1990, 
Journal Committed to Social Change on Race and Ethnicity | Volume 7, Issue 2 | 2021

1995). These two phases serve as the organizing principles for six linear statuses of white racial identity development. Phase one, abandonment of racism occurs through contact with People of Color (contact), conscious yet conflicted recognition of one's own whiteness (disintegration), and acknowledgement of one's whiteness and assumption of white racial superiority (reintegration). The individual moves out of the abandonment of racism phase when they question their beliefs in the superiority of whiteness and their justifications for racism. Thus, begins phase two, defining a non-racist white identity. The individual is now actively questioning their beliefs about racial superiority and inferiority (pseudo-independent), rejecting their previously held stereotypes about racial groups and learning accurate information about being white (immersion/emersion), and finally internalizing and applying their new understanding of whiteness to their daily life (autonomy).

A non-racist white identity, however, is not simply achieved and maintained. Individuals can exhibit multiple statuses at the same time (Thompson \& Carter, 1997). While Helms (1990) presented this model as a linear process, subsequent work has suggested that people can both progress and regress in their white identity development (Malott et al., 2015; Thompson \& Carter, 1997). Additionally, Bowman (2013) found that "interracial interactions are consistently associated with improved college student outcomes; therefore, interactions with students from all racial backgrounds may be a powerful means for bolstering student growth" (p. 326).

Critics of Helms's model $(1984,1990)$ and similar approaches to understanding white racial identity construction contend that such conceptualizations attend to how the White person views racialized others, rather than focusing on their internal sense of self 
Journal Committed to Social Change on Race and Ethnicity | Volume 7, Issue 2 | 2021

(Gallagher, 2000; Reason, 2015). White identity development constructs may serve to essentialize and de-contextualize understandings of whiteness (Gallagher, 2000;

Thompson, 1999). Furthermore, such white racial identity constructs set selfactualization as the goal, which implies White people can be either bad (before selfactualization) or good (once self-actualization has been reached) (Reason, 2015; Thompson, 2003). To account for racial identity development, we also draw on queer of color critique in our application of Helms's model. Queer of color critique engages intersectionality (Crenshaw, 1991) and components of queer theory to bring forward analysis on the basis of racialized subjectivities and sexuality (Blockett, 2018). These critiques and theoretical approaches inform our application of Helms's $(1984,1990)$ white racial identity development model.

We do not advance this framework to have checkboxes of attitudes and behaviors, which could demonstrate the "[valuing] a positive sense of self over political action" (Reason, 2015, p. 81). Rather, we seek to leverage it to explore the complexities of understanding one's privilege and existence within a racist sociopolitical system as well as one's role in changing that system (Renn \& Reason, 2013).

\section{Methods}

This project utilized data from the longitudinal interview component of a national study of LGBTQ+ students. The present qualitative project is a single-site phenomenology framed through an LGBTQ ecological systems perspective (Woodford et al., 2016). It operated from both an interpretivist epistemological stance, wherein truth is understood to be many and constructed through discourse, and a critical stance, 
Journal Committed to Social Change on Race and Ethnicity | Volume 7, Issue 2 | 2021

recognizing socio-political dynamics' influences on truth and its construction (Sipe \& Constable, 1996).

Researchers conducted semi-structured interviews with 20 college students between 2013 and 2017. Twelve participants held monoracial white identities, and we selected them for the present analysis. These interviews focused on students' identity development, campus experiences, awareness and use of campus resources, and sense-making of contemporary national events.

\section{Participants and Data Collection}

The longitudinal study's original cohort of participants comprised 13 first-year undergraduate students at Midwestern University (MU), a large, public, research university in the Midwest. These students were recruited during events focused on introducing first-year LGBTQ+ students to campus communities and through LGBTQ+ student groups, from which the principal investigator crafted a purposive sample (Palys, 2008). The research team recruited additional students to the study during the second and third years through snowball sampling (Morgan, 2008) for a final cohort of 20 students. All students had entered MU in fall 2013.

The full study cohort identified across a range of sexual orientations, gender identities, and racial identities. We selected the 12 monoracial White students for this analysis. Among the 12, by sexual orientation 7 identified as gay, 2 as bisexual, 2 as asexual, 1 as lesbian, and 1 as queer. Participants reported the following gender identities at the beginning of the study: six identified as men, four as women, one as transgender, and one as non-binary. 
Journal Committed to Social Change on Race and Ethnicity | Volume 7, Issue 2 | 2021

The research team conducted a series of 13 semi-structured interviews throughout the 4-year period (4 interviews each in years 1 and 2, 3 interviews in year 3, and 2 interviews in year 4) with all possible participants. These interviews focused on a range of topics, including success, identity development, and relevant national events. While the protocols were not developed specifically to center race or to explore white identity, questions throughout the protocols offered entry points for participants to reflect on many facets of their identities, including race if they wished.

The present study focused on the 12 monoracial White students' experiences and meaning making in relation to race. Of the 13 total possible interviews per student, we narrowed our attention to 5 interviews from across the 4 years of the longitudinal study (30 interviews total in the data set we analyzed). These interviews were selected for analysis based on their protocols including questions about students' multiple identities, communities, and sense making of national events (e.g., the 2015 Black Lives Matter movement).

\section{Data Analysis}

Joining the research team after data collection was completed, Chelsea (Author 1) analyzed the selected transcripts inductively, examining the available evidence to begin to make inferences (Saldaña, 2011). Chelsea coded previously transcribed interviews using DeDoose qualitative analysis software. Using descriptive coding, which relies on nouns to describe briefly the topic present in the data (Saldaña, 2011), and established a working catalogue of participants' engagement with and discussion of race. Subsequently, she analyzed these descriptive codes for frequency and relationships, from which themes were developed (Saldaña, 2011). For example, data 
Journal Committed to Social Change on Race and Ethnicity | Volume 7, Issue 2 | 2021

from both "white identification" and "non-engagement" codes informed findings about white racial awareness and identification. Kris (Author 2) debriefed codes and initial themes with Chelsea. As a co-PI on the larger project from which they drew this data, Kris served both as a knowledgeable insider to the overall project and as a debriefer and collaborator during the themes and findings development process.

\section{Positionality}

We bring our identities, as well as our lived, academic, and practitioner experiences to this project, consistent with our interpretivist and critical approaches. Both authors identify as White, queer, cisgender women. As a scholar-practitioner, Chelsea seeks to amplify the experiences of minoritized students and improve college environments to advance social justice. She comes to this study cognizant of her own white racial development, which was catalyzed during her coming out journey in college. She is deeply committed to racial justice, especially working within White queer and trans communities to dismantle white supremacy. Kris, who was PI of a national study of LGBTQ+ college students, has advocated for minoritized students through her scholarship and practice. Working from multiple positions of privilege (White, cisgender, tenured faculty member, US citizen), she aligns her commitments to racial justice with the opportunities afforded through this privilege to elevate critiques of whiteness and amplify the work of Queer and Trans People of Color.

\section{Trustworthiness}

The present analysis relied on data from a larger longitudinal project, the purpose of which was to better understand LGBTQ+ student success and development. While protocols included questions with reference to race, this project was not exclusively or 
Journal Committed to Social Change on Race and Ethnicity | Volume 7, Issue 2 | 2021

even expressly interested in race. As such, students may have offered more authentic, less guarded, and less performative comments about race. Chelsea was not involved in study design or data collection processes. Thus, Chelsea approached data analysis without any familiarity or preconceived notions of participants or potential findings. Both authors engaged in reflexive practices individually and through team debriefing, as we considered our own identities, commitments, and relationships to the research questions and data sources. Finally, we triangulated data from participants' multiple interviews across their years of participation in the study to clarify, challenge, and affirm our analysis (Rossman \& Rallis, 2017).

\section{Limitations}

While this study offers insights into racial identity development and racial awareness among White LGBTQ+ students, it is important to address its limitations. First, the participants in this study do not represent the entirety of the monoracial White LGBTQ+ college student population. The research team drew participants from a single predominantly white institution, thus limiting applicability to other contexts (e.g., different institution types, regions). The team recruited students through outreach to explicitly LGBTQ+-focused offices, programs, and groups, which likely biased the sample to students who were relatively comfortable identifying and discussing their LGBTQ+ identity(ies).

This study engages in secondary analysis of previously collected data. The study from which this data comes did not focus explicitly on race. As previously discussed, the broader framing of this study may have benefited this project, offering a more authentic snapshot of participants' understandings of race. However, the interview protocols did 
Journal Committed to Social Change on Race and Ethnicity | Volume 7, Issue 2 | 2021

not delve as deeply into the intersections of sexual orientation, gender, and race as they would have in a more explicit study of these multiple identities. Further, students were not primed to discuss race as it was not a clear focus of the study. This framing creates opportunities for researchers to observe the statements and silences about race when it might not be considered central to the conversation. Yet, the limitation is that these participants may have had much more to say about race if they had been asked directly or expecting to talk about their racial identities.

\section{Findings}

Our findings centered on three major themes. First, White LGBTQ+ college students struggled to discuss race and white privilege in early interviews. For many, their white identity was not viewed as salient. Next, there was some change over the four years of interviews, with students offering more nuanced perspectives around their white identities and race more broadly. Finally, interpersonal experiences, academic engagement, and national events provided access points for White LGBTQ+ students to talk about race and whiteness.

\section{Avoidance and Conflicted Recognition of White Identity}

Participants struggled to recognize their white racial identity, consistent with Helms's (1990) disintegration status. In the first interview, students were asked which of their identities were important to them:

everyone at MU holds multiple identities: sexual orientation, gender identity, race, ethnicity, nationality, ability, religion, first in the family to go to college, academic major, and so on. You'll see in your residence hall and classes that students come from all over [this state], all over the U.S. and the world, to express themselves in different ways and try on different identities in college. In addition to your LGBTQ identity, what aspects of your identity feel important to you as you enter MU? 
Journal Committed to Social Change on Race and Ethnicity | Volume 7, Issue 2 | 2021

In response to this question and variations of this multiple identities question in the first two years, White students rarely identified race as an important or salient part of their identities.

When students did reference race or ethnicity in response, they minimized their racial and ethnic identities. Sophie cited her confidence as central to her identity, but "my identity as being White seems kind of meh, whatever. Most people are, so..." Brett responded, "music would be one of the things, but that leads into a bigger thing, probably leadership or just being creative. I'm not really into the whole-there's no ethnicity that I try to incorporate into who I am." Both Sophie and Brett offered immediate responses that did not relate to their social identities. When they continued, they diminished the role of race and ethnicity in their identity.

While a white racial identity was not salient to students in their first year, multiple students described the demographics and cultural norms of their communities of origin. Comparing MU to where Sophie grew up, she emphasized the homogeneity of her hometown, "it just seemed kinda normal in my area [...] we were all White. We were all Christian. We were all this. We were all that." Jake reflected:

It was interesting being a gay man growing up in the area because, like I said already, it's a conservative kind of like-to-stick-to-the-old ways of living. There's not any diversity, really. I think we have maybe one-we had one Black girl who went to my school. Everyone else was White. No other color.

At MU, Jake shared, "I find it really refreshing to have so much color and diversity," a clear departure from his high school. Both Sophie and Jake articulated an awareness of their lack of exposure to people from different racial and ethnic backgrounds, among other identities, in their communities of origin. These reflections may indicate that White students from homogenous communities were beginning to encounter People of Color 
Journal Committed to Social Change on Race and Ethnicity | Volume 7, Issue 2 | 2021

(Helms's (1990) contact status) in college and to gain awareness of their racial identity. Although most students did not comment on their white racial identity in early interviews, those who did demonstrated recognition of their white identity in relation to their homogenous communities of origin.

Increased Awareness over Time

By their third and fourth years, students generally broached race—both their own and others'-with greater awareness and ease. When asked to complete an identity wheel activity in which they discussed the importance of different identities, students were more forthcoming about their understanding of their white racial identity than in previous open-ended questions about their important identities. Though not included in Jon's most salient identities, he shared, "I also included in here that I'm a cisgender White male because I think that's important. That gives me advantages that I'm not even aware of." Morgan described the race portion they included on their identity wheel:

my White identity got a fairly large piece compared to some of these other ones just because l'm being pretty cognizant of who's with me in spaces and what I can do in spaces to make them more accessible and comfortable to People of Color. I think that that happens more than it used to for me.

These comments, though brief, suggest that both Jon and Morgan were exhibiting signs of moving through the Helms's (1990) model's reintegration status and towards pseudoindependence. Both acknowledge benefiting from white privilege. Jon does not offer more details about how he thinks or acts given these "advantages." In contrast, Morgan's comment moved beyond awareness to indicating a desire to make spaces more accessible to People of Color. However, the motivation behind this desire 
Journal Committed to Social Change on Race and Ethnicity | Volume 7, Issue 2 | 2021

remained unclear; they could be motivated by guilt, lingering beliefs about white superiority, or perhaps a desire to change their own behavior to be more anti-racist.

Although several students demonstrated increased ability to discuss race, this was not consistent across all participants. For example, Aaron, a participant all four years of the study, claimed to be "very vocal" about racial justice issues in Year 3, but claimed in the same interview that his identities of "gay, White, and male [...] don't play a large factor into my decisions or how I go about my daily life." When asked about the Pulse nightclub shooting in Orlando and ongoing BLM events in Year 4, he did not talk about race. Students demonstrated increased willingness to name their white identities over time. However, they varied greatly in their sense-making of their racial identity's influence in their lives and the role of race in society.

\section{Catalysts for Racial Awareness}

As students articulated more complex understandings of their own racial identities and race in U.S. society, their insights paired with external catalysts. When students discussed race, they most commonly referenced interpersonal relationships, academic experiences, and major national news and media. Interacting with people of different racial identities and gaining awareness of race in society supported students' white racial identity development toward more complex statuses (Bowman, 2013; Helms, 1990).

Interpersonal relationships. Students most frequently discussed race in connection to describing their interactions and relationships with People of Color. These experiences prompted participants to consider their identities and experiences in 
Journal Committed to Social Change on Race and Ethnicity | Volume 7, Issue 2 | 2021

relation to difference. Students engaged with People of Color and subsequently considered their own racial identity.

Sophie grappled with the intersections of race and class when she "met someone who was Black and raised in [a major city], but also in poverty like me and had a very similar background, even though we were two different races." This interaction prompted Sophie to find commonalities where she had previously seen only difference. Brett offered the example of his friend group:

One is super Catholic conservative, and the other one is a White girl from [City], and then another one is Arabic Muslim who is very religious as well, and there's me, the gay guy. We call ourself the diverse team. [...] We're all very open to each other, and we all accept each other, no matter what.

Intimate relationships also provided new perspectives on race. Anna shared, "My girlfriend isn't White, so we've had to deal with being treated different. I've had to deal with being treated differently when I'm in the car with her versus when I'm not." White LGBTQ+ students' relationships with People of Color often served as a catalyst for learning about and engaging with their own racial identities.

Academic and co-curricular experiences. Having dedicated academic space and time to engage with others about identity and pressing societal issues can be important tools for dispelling harmful myths and fostering more accurate understandings of the influence of race on society. This learning supported White individuals as they developed their racial identities, especially those exhibiting characteristics of immersion/emersion and autonomy (Helms, 1990).

Jon chose to participate in a living-learning community designed to foster community across difference during his first year. He described his experience, "I really like that there are so many different perspectives that you get. We talk about different 
Journal Committed to Social Change on Race and Ethnicity | Volume 7, Issue 2 | 2021

things. We talk about class. We talk about gender. We talk about race. We'll talk about anything." Morgan shared that,

definitely conversations [about policing are] happening in my queer circles. [We talked] about that quite a bit last year, especially. Talking definitely in my [College of Public Affairs] classes as well. Last year in one of my classes we read a whole book called The New Jim Crow by Michelle Alexander.

After previously learning about the devastating effects of police violence and the criminal justice system on communities of Color, and especially for Black men, Morgan then had the background to engage in challenging conversations in the midst of the Black Lives Matter movement. Students drew on academic and co-curricular experiences to better understand and challenge race, its role in society, and its manifestations in their lives.

National news and media. These interviews, conducted between 2013 and 2017, overlapped with significant media representation and national events around race and LGBTQ+ issues. Interview protocols included questions about students' perceptions of Black Lives Matter, same-sex marriage, Caitlyn Jenner's public transition, and the television series Orange is the New Black. While not all students spoke directly about the racial dynamics at play, many used the opportunity to provide commentary about the intersections of race and LGBTQ+ identities.

In their third year of college and the study, several students voiced concerns over the representation of LGBTQ+ people and identities in popular culture. Morgan expressed frustrations with the focus on Caitlyn Jenner's transition, "I think it's a little erasing in terms of now we have a White, rich face to put to this and that might - that's all the representation that they need." Morgan's mom was trying to understand more about trans identities and issues, so she was "pretty much marathoning [Caitlyn 
Journal Committed to Social Change on Race and Ethnicity | Volume 7, Issue 2 | 2021

Jenner's TV show]." In response, Morgan "talked [to their mom] a little bit about [Jenner's] representativeness of the trans community." Jon referenced the movie Stonewall as an example of whitewashing the LGBTQ+ movement:

There's been a lotta controversy surrounding it because the main characters [in the movie] are White when in actuality the-one of the biggest people behind Stonewall was a Black trans woman. It still happens. Even a community who is oppressed still oppresses, even if we don't see it that way.

Both Morgan and Jon were critical of mainstream media representations of the LGBTQ+ community, which emerge from both within and outside of the LGBTQ+ community.

Black Lives Matter (BLM) prompted particularly keen analyses from students. For example, Joe spoke at length about the prominence of BLM in their consciousness.

They had challenging conversations with their family about BLM:

my family was like well, he shouldn't have been doing that anyway. It's like well, he shouldn't have been killed for it. And they didn't get that. [...] my family's all White, so there's no people who are actually experiencing racism in my house.

Joe also hoped that BLM would be a galvanizing force within LGBTQ+ communities:

a lot of LGBT communities end up being White [gay and lesbian] discussions [...] There's a lot of racism in the LGBT community I feel, and I feel like these movements are really good to bring up discussions to help fight that racism that seems to be epidemic.

Joe's reflections demonstrate awareness of the challenges that come with talking about race and the necessity of engaging in those conversations at multiple levels - from interpersonal to systemic. Across these examples, students contested the assumed superiority of White people and their learning about historical and present treatment of People of Color, consistent with the immersion/emersion stage (Helms, 1990). National news and media created opportunities for students to interrogate how race shapes their experiences of LGBTQ+ communities and beyond. 
Journal Committed to Social Change on Race and Ethnicity | Volume 7, Issue 2 | 2021

\section{Discussion}

Helms's (1990) white racial identity development model provided a useful framework for understanding the racial awareness and White racial identity development of the 12 monoracial White LGBTQ+ students in our longitudinal qualitative study. Taken together, the major themes of avoidance and conflicted recognition of white identity, increased awareness over time, and catalysts for racial awareness offered insights into these White LGBTQ+ students' identity development processes. The findings suggest that White LGBTQ+ students enter college with limited understanding of their white racial identities and gain more complex conceptions throughout their college experiences. Of the catalysts often referenced by participants, interpersonal relationships and academic experiences are most obviously under the purview of colleges and universities, which are themselves embedded in social structures that include national news and media.

In early interviews, students were most likely to express attitudes consistent with statuses related to rejecting racism (contact with People of Color, disintegration when becoming conscious of their own white identity, and acknowledgement of their white identity). Yet, many students did not acknowledge the role of race or their racial identity in early interviews, exhibiting isolation from and ignorance of racial issues (Cabrera, 2018). Many students appeared to gain awareness and nuance in later years, moving beyond rejecting racism towards speaking about adopting a non-racist white identity (Helms, 1990).

Some students' increasingly complex ways of understanding their own racial identities and the ways race operates in society manifested in both attitudes and 
Journal Committed to Social Change on Race and Ethnicity | Volume 7, Issue 2 | 2021

actions. For example, Joe challenged his family to examine their reactions to BLM events and Morgan shared their critiques of Caitlyn Jenner's so-called trans representation with their mom. While reflections on racial attitudes were more prevalent in our findings, reports of anti-racist actions suggest that shifting attitudes and increased knowledge may influence behaviors. Returning to Reason's (2015) call to look beyond attitudes for political action, we observed some students, particularly Joe and Morgan, describe both anti-racist attitudes and their participation in actions to disrupt white supremacy.

However, Aaron's example of claiming to be both a vocal advocate for racial justice and not viewing his racial identity as salient highlighted that white racial identity development can be uneven, nonlinear, and dynamic (Malott et al., 2015; Thompson \& Carter, 1997). Like others, Aaron had access to similar academic and co-curricular opportunities, as well as news and popular media. He is generally aware of the role of race in society, yet he demonstrated little identity development broadly, and in his white racial identity specifically. Similar to Cabrera's (2012) analysis that "just because one proactively combats racism does not imply that one has moved beyond race" (p. 394), developing racial awareness is part of racial identity development but awareness does not inherently promote identity development. Aaron's lack of substantive reflection, engagement, and development around race led us to probe why Aaron did not demonstrate substantive or sustained racial identity development, and what interventions could have prompted such development.

Evidence of white racial identity development often came paired with references to learning from friends, partners, and academic experiences, consistent with Cabrera's 
Journal Committed to Social Change on Race and Ethnicity | Volume 7, Issue 2 | 2021

(2012) findings about cross-racial interactions and multicultural education. Although this study focused exclusively on White students, students of all racial backgrounds have been shown to benefit from interracial interactions, although the benefits can differ in magnitude and type (Bowman, 2013; Tropp \& Pettigrew, 2005). The participants who shared experiences of learning through experiences with People of Color cited their own reflections and learning either from a distance (Sophie) or from people with whom the White students had developed trusting relationships (Brett and Anna). However, this finding does not imply that People of Color are responsible for educating their White friends, partners, or classmates. Indeed, to expect People of Color to educate White people and to demand People of Color to perform additional labor for the benefit of White people is to allow "oppressors [to] maintain their position and evade responsibility for their own actions" (Lorde, 1980, para. 2).

National news and media furthered these White students' ability and willingness to engage in conversations around race and galvanized some students into action. The study was conducted between 2014 and 2017, a period of time with intense attention to racial tensions in the U.S. and growing awareness of LGBTQ+ issues. The national conversations around race, gender, and sexuality may have contributed to students' racial identity development processes (Grier-Reed et al., 2017).

\section{Implications and Future Directions}

The findings from this study suggested that these White LGBTQ+ students entered college with little awareness of their racial identities and limited capacity for discussing race. While these students gradually gained interest in and facility with discussing race and their own white racial identity, they often did so in relation to others 
Journal Committed to Social Change on Race and Ethnicity | Volume 7, Issue 2 | 2021

or through classes they chose to take. Others did not exhibit racial identity development. This study advances our understanding of when and how White LGBTQ+ college students grapple with race, white supremacy, white immunity, and their own racial identity. Our findings bear a notable resemblance to Cabrera's $(2012,2014,2018)$ findings in studies of White college men. Of particular concern, however, is that our findings rely on interviews conducted about a decade later than Cabrera's, suggesting the ongoing challenge of promoting White racial identity development as well as antiracist commitments and actions. These findings have implications for both practice and research.

This study highlighted the power of engaging differing experiences, especially in interpersonal and academic settings, for advancing racial identity development among White LGBTQ+ students. It is imperative for student affairs educators to address race and racism with all students, and especially white students. Practitioners in LGBTQ+ campus resource centers or who advise LGBTQ+ student organizations may consider opportunities to expose White students to narratives and educational programs that present accurate and nuanced insights into white identity and the lived experiences of People of Color without relying on People of Color to engage in that teaching. Academic advisors and instructors may also consider the influence of academic experiences that center discussions of race, racism, power, and oppression when advising students as well as designing courses and curricula. Faculty must do their own work to confront race in their professional (and we would also argue personal) lives, investing in their own learning and developing skills to be ready to talk about race in their classrooms. National news and media prompted conversations and reflection among White LGBTQ+ 
Journal Committed to Social Change on Race and Ethnicity | Volume 7, Issue 2 | 2021

students, which suggests that these moments can be leveraged for greater learning both in academic and co-curricular spaces; a queer of color critique would suggest that use of news and media should include critical analysis of these sources and their motivations to maintaining the status quo.

This study further offers implications for both white racial identity and Critical Whiteness Studies (CWS) scholarship, as well as scholarship focused on LGBTQ+ students. Scholars should continue to advance CWS in higher education scholarship, paying particular attention to multiple identities (including gender and sexuality) and how they interact with racial identity. For example, how might White LGBTQ+ students' racial identity development processes compare to those of White, straight, cisgender students? There are opportunities to engage with and extend racial ally development work (e.g., Broido, 2000; Reason et al., 2005), which is a logical extension of this present study. Future studies of LGBTQ+ students should explore race directly, rather than relying on secondary data analysis. Additional work with queer of color critique in higher education would bring important critical insights into the field. Finally, future longitudinal studies of LGBTQ+ students could benefit from including a racial identity development component to characterize students' development more robustly.

\section{Conclusion}

These 12 White LGBTQ+ students began college by either avoiding the topic of race or by downplaying the role of whiteness in their lives. Over time, many students gained increased awareness and facility talking about their white racial identities. This progress was often discussed in association with personal relationships, academic experiences, and contemporary news and media. Evidence of this progression and the 
Journal Committed to Social Change on Race and Ethnicity | Volume 7, Issue 2 | 2021

catalysts for this development offer insights to student affairs professionals, institutional decision makers, and scholars around potential pathways for positive white racial identity development in LGBTQ+ communities.

This study contributes to both the literature on LGBTQ+ students and how students learn about White identity. Jon's statement that, "even a community who is oppressed still oppresses, even if we don't see it that way," highlights the need for White students to gain racial consciousness and to take active roles in fostering safer,

braver spaces for LGBTQ+ students of all races. This reflection also suggests that some White LGBTQ+ people can gain awareness of how they participate in the oppression of others, providing a framework for them to then engage in the work of understanding white supremacy and their responsibility for dismantling it.

\section{References}

Abes, E. S., \& Jones, S. R. (2004). Meaning-making capacity and the dynamics of lesbian college students' multiple dimensions of identity. Journal of College Student Development, 45(6), 612-632. https://doi.org/10.1353/csd.2004.0065

Allport, G.W. (1954). The nature of prejudice. Addison-Wesley.

Beattie, I. R., Van Dyke, N., \& Hagaman, N. (2021). What do we know about LGBQ+ college student academic experiences and outcomes? Sociology Compass, 15(3). https://doi.org/10.1111/soc4.12862

Blockett, R. A. (2018). Thinking with queer of color critique: A multidimensional approach to analyzing and interpreting data. In R. Winkle-Wagner, J. LeeJohnson, \& A. N. Gaskew, (Eds.), Critical Theory and Qualitative Data Analysis in Education (pp. 109-122). Routledge.

Bonilla-Silva, E. (2017). Racism without racists: Color-blind racism and the persistence of racial inequality in America (5th Ed.). Rowman \& Littlefield Publishers.

Bowman, N. A. (2013). The conditional effects of interracial interactions on college student outcomes. Journal of College Student Development, 54(3), 322-328. https://doi.org/10.1353/csd.2013.0026

Bowman, N. A., \& Park, J. J. (2015). Not all diversity interactions are created equal: Cross-racial interaction, close interracial friendship, and college student outcomes. Research in Higher Education, 56, 601-621. https://doi.org/10.1007/s11162-015-9365-z

Broido, E. M. (2000). The development of social justice allies during college: A phenomenological investigation. Journal of College Student Development, 41(1), 3-18. 
Journal Committed to Social Change on Race and Ethnicity | Volume 7, Issue 2 | 2021

Cabrera, N. L. (2012). Working through Whiteness: White, male college students challenging racism. The Review of Higher Education 35(3), 375-401. https://doi.org/10.1353/rhe.2012.0020

Cabrera, N. L. (2014). Exposing whiteness in higher education: White male college students minimizing racism, claiming victimization, and recreating white supremacy. Race Ethnicity and Education, 17(1), 30-55. https://doi.org/10.1080/13613324.2012.725040

Cabrera, N. L. (2017). White immunity: Working through some of the pedagogical pitfalls of "privilege." Journal Committed to Social Change on Race and Ethnicity, 3(1), 78-90. https://doi.org/10.15763/issn.2642-2387.2017.3.1.77-90

Cabrera, N. L. (2018). White guys on campus: Racism, White immunity, and the myth of "post-racial" higher education. Rutgers University Press.

Cabrera, N. L., Watson, J. S., \& Franklin, J. D. (2016). Racial arrested development: A critical Whiteness analysis of the campus ecology. Journal of College Student Development 57(2), 119-134. https://doi.org/10.1353/csd.2016.0014

Crenshaw, K. (1991). Mapping the Margins: Intersectionality, Identity Politics, and Violence against Women of Color. Stanford Law Review, 43(6), 1241-1299. https://doi.org/10.2307/1229039

Duran, A. (2019). Queer and of color: A systematic literature review on queer students of color in higher education scholarship. Journal of Diversity in Higher Education, 12 (4), 390-400. https://doi.org/10.1037/dhe0000084

Duran, A., Dahl, L. S., Prieto, K., Hooten, Z., \& Mayhew, M. J. (2020). Exposing the intersections in $\mathrm{LGBQ}+$ student of color belongingness: Disrupting hegemonic narratives sustained in college impact work. Journal of Diversity in Higher Education. http://doi.org/10.1037/dhe0000222

Duran, A., Jackson, R., \& Lange, A. C. (2020). The theoretical engagements of scholarship on LGBTQ+ people in higher education: A look at research published between 2009 and 2018. Journal of Diversity in Higher Education. https://doi.org/10.1037/dhe0000284

Friedensen, R. E., Kimball, E., Vaccaro, A., Miller, R. A., \& Forester, R. (2021). Queer science: Temporality and futurity for queer students in STEM. Time \& Society. https://doi.org/10.1177/0961463X211008138

Gallagher, C. A. (2000). White like me? Methods, meaning, and manipulation in the field of White studies. In F. W. Twine \& J. W. Warren (Eds.), Racing research, researching race: Methodological dilemmas in critical race studies (pp. 67-92). New York University Press.

Garvey, J. C., Squire, D. D., Stachler, B., \& Rankin, S. (2018). The impact of campus climate on queer-spectrum student academic success. Journal of LGBT Youth, 15(2), 89-105. https://doi.org/10.1080/19361653.2018.1429978

Grier-Reed, T., Houseworth, J., \& Diehl, D. (2017). Breaking down walls and building bridges: A study of cross-racial interactions across two predominantly White campuses. Journal Committed to Social Change on Race and Ethnicity, 3(2), 223. https://doi.org/10.15763/issn.2642-2387.2017.3.2.1-23

Grillo, T., \& Wildman, S. M. (2018). Obscuring the importance of race: The implications of making comparisons between racism and sexism (or other-isms). In V. Lea, D. 
Journal Committed to Social Change on Race and Ethnicity | Volume 7, Issue 2 | 2021

E. Lund, \& P. R. Carr (Eds.), Critical multicultural perspectives on Whiteness (pp. 157-169). Peter Lang Publishing.

Helms, J. E. (1984). Toward a theoretical explanation of the effects of race on counseling: A Black and White model. The Counseling Psychologist, 12(4), 153165. https://doi.org/10.1177/0011000084124013

Helms, J. E. (Ed.). (1990). Black and White racial identity: Theory, research, and practice. Greenwood Press.

Helms, J. E. (1995). An update of Helm's White and people of color racial identity models. In J. G. Ponterotto, J. M. Casas, L. A. Suzuki, \& C. M. Alexander (Eds.), Handbook of multicultural counseling (pp. 181-198). SAGE Publications.

Johnson, J. M., \& Javier, G. (Eds.). (2017). Queer people of color in higher education. Information Age Publishing.

Joyce, S. B., \& Cawthon, T. (2017). The influence of Whiteness on the group socialization of fraternity men. Journal Committed to Social Change on Race and Ethnicity, 3(2), 25-61. https://doi.org/10.15763/issn.2642-2387.2017.3.2.24-61

Lange, A. C., Duran, A., \& Jackson, R. (2019). The state of LGBT and queer research in higher education revisited: Current academic houses and future possibilities. Journal of College Student Development 60(5), 511-526. https://doi.org/10.1353/csd.2019.0047

Leonardo, Z. (2009). Race, Whiteness, and education. Routledge.

Lichter, D. T., Parisi, D., \& Taquino, M. C. (2017). Together but apart: Do US whites live in racially diverse cities and neighborhoods? Population and Development Review, 43(2), 229-255. https://doi.org/10.1111/padr.12068

Linley, J. L., Renn, K. A., \& Woodford, M. R. (2018). Examining the ecological systems of LGBTQ STEM majors. Journal of Women and Minorities in Science and Engineering, 24(1), 1-16. https://doi.org/10.1615/JWomenMinorScienEng.2017018836

Logie, C. H., \& Rwigema, M. J. (2014). "The normative idea of queer is a White person": Understanding perceptions of White privilege among lesbian, bisexual, and queer women of color in Toronto, Canada. Journal of Lesbian Studies, 18(2), 174-191. https://doi.org/10.1080/10894160.2014.849165

Lorde, A. (1980, April). Age, race, class and sex: Women redefining difference [Paper presentation]. Copeland Colloquium, Amherst College, Amherst, MA.

Malott, K. M., Paone, T. R., Schaefle, S., Cates, J., \& Haizlip, B. (2015). Expanding White racial identity theory: A qualitative investigation of Whites engaged in antiracist action. Journal of Counseling and Development, 93(3), 333-343. https://doi.org/10.1002/jcad.12031

Marine, S. B., \& Nicolazzo, Z. (2014). Names that matter: Exploring the tensions of campus LGBTQ centers and trans* inclusion. Journal of Diversity in Higher Education, 7(4), 265-281. http://doi.org/10.1037/a0037990

Matias, C. E. (2016). Feeling White: Whiteness, emotionality, and education. Sense Publishers.

Maxwell, K. E. (2018). Deconstructing Whiteness, discovering the water. In V. Lea, D. E. Lund, \& P. R. Carr (Eds.), Critical multicultural perspectives on Whiteness (pp. 181-192). Peter Lang Publishing. 
Journal Committed to Social Change on Race and Ethnicity | Volume 7, Issue 2 | 2021

McCoy, S. D. (2018). Where is my place?: Queer and transgender students of color experiences in cultural centers at a predominantly White university [Doctoral dissertation, University of Wisconsin - Madison]. ProQuest Dissertations and Theses Global.

McCready, L. T. (2004). Some challenges facing queer youth programs in urban high schools. Journal of Gay \& Lesbian Issues in Education, 1(3), 37-51. https://doi.org/10.1300/J367v01n03_05

Mclntosh, P. (1989). White privilege: Unpacking the invisible knapsack. Peace and Freedom, 10-12.

Miller, R. A., \& Vaccaro, A. (2016). Queer student leaders of Color: Leadership as authentic, collaborative, culturally competent. Journal of Student Affairs Research and Practice, 53(1), 39-50. https://doi.org/10.1080/19496591.2016.1087858

Mitchell, D., Jr., \& Means, D. R. (2014). "Quadruple consciousness": A literature review and new theoretical consideration for understanding the experiences of Black gay and bisexual college men at predominantly White institutions. Journal of African American Males in Education, 5, 23-25.

Morgan, D. L. (2008). Snowball sampling. In L. Given (Ed.), The SAGE encyclopedia of qualitative research methods. SAGE Publications. https://doi.org/10.4135/9781412963909.n425

Nicolazzo, Z. (2017). Trans* in college: Transgender students' strategies for navigating campus life and the institutional politics of inclusion. Stylus Publishing.

Omi, M. \& Winant, H. (2015). Racial formation in the United States (3rd ed.). Routledge.

Ortiz, S. M., \& Mandala, C. R. (2021). "There is queer inequity, but I pick to be happy": Racialized feeling rules and diversity regimes in university LGBTQ resource centers. Du Bois Review. Advance online publication. https://doi.org/10.1017/S1742058X21000096

Palys, T. (2008). Purposive sampling. In L. Given (Ed.), The SAGE encyclopedia of qualitative research methods. SAGE Publications. https://doi.org/10.4135/9781412963909.n349

Park, J. J., \& Bowman, N. A. (2015). Religion as bridging or bonding social capital: Race, religion, and cross-racial interaction for college students. Sociology of Education, 88(1), 20-37. https://doi.org/10.1177/0038040714560172

Pitcher, E. N., Camacho, T. P., Renn, K. A., \& Woodford, M. R. (2018). Affirming policies, programs, and supportive services: Using an organizational perspective to understand LGBTQ+ college student success. Journal of Diversity in Higher Education, 11(2), 117-132. https://doi.org/10.1037/dhe0000048

Reason, R. D. (2015). Engaging White students on multicultural campuses. In S. J. Quaye \& S. R. Harper (Eds.), Student engagement in higher education: Theoretical perspectives and practical approaches for diverse populations (2nd ed., pp. 75-89). Routledge.

Reason, R. D., Roosa Millar, E. A., \& Scales, T. C. (2005). Toward a model of racial justice ally development. Journal of College Student Development 46(5), 530546. https://doi.org/10.1353/csd.2005.0054 
Journal Committed to Social Change on Race and Ethnicity | Volume 7, Issue 2 | 2021

Renn, K. A. (2010). LGBT and queer research in higher education: The state and status of the field. Educational Researcher, 39(2), 132-141. https://doi.org/10.3102/0013189X10362579

Renn, K. A., \& Arnold, K. D. (2003) Reconceptualizing research on college student peer culture. The Journal of Higher Education, 74(3), 261-291. https://doi.org/10.1080/00221546.2003.11780847

Renn, K. A., \& Reason, R. D. (2013). College students in the United States: Characteristics, experiences, and outcomes. Jossey-Bass.

Rossman, G. R., \& Rallis, S. F. (2017). An introduction to qualitative research: Learning in the field (4th ed.). SAGE Publications.

Saldaña, J. (2011). Fundamentals of qualitative research. Oxford University Press.

Self, J. M., \& Hudson, K. D. (2015). Dangerous waters and brave space: A critical feminist inquiry of campus LGBTQ centers. Journal of Gay and Lesbian Social Services, 27(2), 216-245. https://doi.org/10.1080/10538720.2015.1021985

Sipe, L. \& Constable, S. (1996). A chart of four contemporary research paradigms: Metaphors for the modes of inquiry. Taboo: The Journal of Culture and Education, 1, 153-163.

Stewart, D.-L., \& Nicolazzo, Z. (2018). High impact of [whiteness] on trans* students in postsecondary education. Equity \& Excellence in Education, 51(2), 132-145. https://doi.org/10.1080/10665684.2018.1496046

Stewart, D.-L., Renn, K. A., \& Brazelton, G. B. (Eds.). (2015). Gender and Sexual Diversity in U.S. Higher Education: Contexts and Opportunities for LGBTQ College Students (New Directions for Student Services). Jossey-Bass.

Tatum, B. D. (2017). Why are all the Black kids sitting together in the cafeteria?: And other conversations about race (20th Anniversary ed.). Basic Books.

Thompson, A. (2003). Tiffany, friend of people of color: White investments in antiracism. International Journal of Qualitative Studies in Education, 16(1), 7-29. https://doi.org/10.1080/0951839032000033509

Thompson, B. (1999). Subverting racism from within: Linking White identity to activism. In C. Clark \& J. O'Donnell (Eds.), Becoming and unbecoming White: Owning and disowning a racial identity (pp. 64-77). Bergin \& Garvey.

Thompson, C. E., \& Carter, R. T. (1997). Racial identity theory: Applications to individual, group, and organizational interventions. Lawrence Erlbaum Associates.

Tropp, L. R., \& Pettigrew, T. F. (2005). Relationships between intergroup contact and prejudice among minority and majority status groups. Psychological Science, 16(12), 951-957. https://doi.org/10.1111/j.1467-9280.2005.01643.x

Woodford, M. R., Joslin, J. Y., Pitcher, E. N., \& Renn, K. A. (2017). A mixed-methods inquiry into trans* environmental microaggressions on college campuses: Experiences and outcomes. Journal of Ethnic and Cultural Diversity in Social Work, 26(1-2), 95-111. https://doi.org/10.1080/15313204.2016.1263817

Woodford, M. R., Joslin, J. Y., \& Renn, K. A. (2016). LGBTQ students on campus: Fostering inclusion through research, policy, and practice. In P. A. Pasque, N. Ortega, \& J. C. Burkhardt, \& M. P. Ting. (Eds.), Transforming understandings of diversity in higher education: Demography, democracy and discourse (pp. 5780). Stylus. 
Journal Committed to Social Change on Race and Ethnicity | Volume 7, Issue 2 | 2021

Vaccaro, A. (2012). Campus microclimates for LGBT faculty, staff, and students: An exploration of the intersections of social identity and campus roles. Journal of Student Affairs Research and Practice, (49)4, 429-446. 